\title{
Optimum Safety Design Approach Based on Integrated Macro- Ergonomics and Resilience Engineering in a Tile and Ceramic Factory
}

\author{
A. Azadeh *, E. Roudi, V. Salehi
}




\title{
Optimum Design Approach Based on Integrated Macro-Ergonomics and Resilience Engineering in a Tile and Ceramic Factory
}

\begin{abstract}
Integrated resilience engineering (IRE) is a novel approach that has a foresight and proactive attitude towards improving the safety and reliability of complex industrial systems such as tile and ceramic factories. This study is an attempt to present an integrated mathematical approach for analyzing the impact of IRE and macro-ergonomics factors in a tile and ceramic factory. Moreover, this study aims to determine the optimum design approach based on integrated macro-ergonomics and resilience engineering. It also identifies the impact of such integration by Principal Component Analysis (PCA). Data collection was performed in the tile and ceramic factory through questionnaire. Then, the reliability and validity coefficients of the data were calculated through Cronbach's alpha and factor analysis, respectively. Thereafter, the impact of IRE and macro-ergonomics factors is examined by means of data envelopment analysis (DEA) and fuzzy DEA approaches. The results show that the system efficiency is improved by integrating IRE and macro-ergonomics factors. Analysis of variance (ANOVA) also reveals that IRE factors are more effective than macro-ergonomics factors. This study is the first study that presents a robust design approach based on the integration of IRE and macro-ergonomics in a ceramic and tile factory. Second, a unique and integrated approach is presented based on DEA, FDEA, PCA and ANOVA to achieve the above objective. Third, it identifies the weight of each factor through mathematical modeling approach. Fourth, it is a practical approach and may be used to identify the weaknesses and strengths of such systems.
\end{abstract}

Keywords: Tile and Ceramic; Integrated Resilience Engineering (IRE); Macro-Ergonomics; Fuzzy Data Envelopment Analysis (FDEA); Principal Component Analysis (PCA); Analysis of Variance (ANOVA)

\section{Motivation and significance}

In developed and developing countries, causes of accidents at complex industrial systems such as manufacturing industries are investigated. Quite a lot of studies revealed that many of critical incidents have mainly been attributed to design of work systems. However, further inquiries have shown that a combination of many factors, including the lack of human and 
organizational considerations as well as resilience level in such systems have resulted in deficiency of managers and operators; therefore, the occurrence of a large number of incidents has come out. The majority of studies undertaken in IRE and macro-ergonomics field have been qualitative. This study introduces a framework to quantitatively examine the efficiency of operators in workplaces. The major motif of this study is that this study for the first time presents the optimum design approach based on integrated macro-ergonomics and resilience engineering in a ceramic and tile factory. To attain the proposed purposes, it suggests a unique and integrated approach based on DEA, FDEA, PCA and ANOVA. In previous studies, weights of each factor were usually acquired based on expert viewpoint. Thus, it is necessary and important to calculate weights of each factor through a precise mathematical model. Furthermore, it is a practical approach and can be used to identify weak areas and strong points of such systems.

\section{Introduction}

The supposition that most issues related to safety can be answered through the improvement of communications among workforces and managers is one of the limitations of the existing safety research domain. Although communication has a high level of importance, there are some technical matters in an organization which cannot be resolved just through communication. In these areas wherein good communication is essential but not adequate, Macro-ergonomics has a more holistic approach to safety through sociotechnical systems principle in forming a safe and productive work environment (Murphy et al., 2014). Moreover, work related health problems continue to be a severe problem despite the considerable resources invested in ergonomic developments to establish a sounder work environment. It might be assumed that it is due to the fact that ergonomic activities have customarily focused on micro levels of systems, like human-system interfaces related to particular jobs and work environments (Hendrick, 1995). Simultaneously, the capability to meet new demands from the outside world by successfully managing internal changes has become a vital necessity and a matter of survival for organizations (Ingelgard and Norrgren, 2001).

There are some differences between two notions of micro-ergonomics and macroergonomics. Concentrating on man-machine systems, working on the development of workplace and interface design for risk avoidance in the system's day-to-day running are related to micro-ergonomics (Morel et al, 2009). Furthermore, improving the efficiency of 
sociotechnical systems and reviewing the impact of organizational configurations on human performance and on safety are some of the desired goals of macro-ergonomics. Moreover, macro-ergonomics originates from Total Quality Management doctrines (Carayon, 2003), which is an approach of the design of socio-technical systems and primarily performs the following: (i) the number, training and gratification of staff members, (ii) equipment quality and equipment maintenance, (iii) development of the physical environment, (iv) quality of work processes, and (v) economic production that is adequate in quantity and quality. In this way, it attempts to concentrate on the conditions required to enhance a system as a whole. This is not only an analysis technique (Carayon, 2006; Clegg, 2000), but it also offers the characteristic of acting in a systemic (in conjunction with the technical and organizational features), participative, and progressive way.

The prominent concept that accentuates the crucial influence of social and organizational factors on the design of safe and operative work systems, processes and equipment items is macro-ergonomics. Macro-ergonomics highlights the crucial nature of organizational factors in the design of creative processes and safe work systems and, thereby, it exerts a vital impact on traditional human factors and ergonomics (Hendrick and Kleiner, 2002). By concentrating on ergonomics, some outcomes such as safety, health, comfort, quality, productivity, and satisfaction may be well affected (Hendrick, 2002) and it is obvious that the job design and sociotechnical system, or macro-ergonomics concept, are inevitable for a successful outcome (Nagamachi, 1995).

Hendrick and Kleiner (2001) defined macro-ergonomics as a top-down sociotechnical system approach to the design of organizational and work system structures. They also defined macro-ergonomics as the application of the overall work-system design of individual jobs and human-machine and human-software interfaces of a new method to the interaction between organizational issues and the technology applied in the organization. In this way, a fully coordinated work system is guaranteed. System of ergonomics arose within the UK and Europe in the 1960s (Katz and Kahn, 1966). By 1986, conceptualization of the ergonomics of work systems had been developed to the point of recognizing it as a distinct sub-discipline. At that time, it became officially recognized as macro-ergonomics (Hendrick, 1986a; Hendrick, 1986b).

Macro-ergonomics is involved with improving the structure and related processes of work systems. Therefore, an understanding of macro-ergonomics first requires an understanding of the key dimensions of the work system structure. Understanding of the particular sociotechnical features of a given work system will lead us to macro-ergonomically 
optimizing these key dimensions of the work system's organizational structure. In fact, the purpose of strategies including macro-ergonomics is to enhance the performance of sociotechnical systems and study the influences of organizational structures on safety and human behavior (Azadeh et al., 2017). In addition, the lack of ergonomics rules influences efficiency, productivity and also the quality of work condition in workplaces (Bertolini, 2007; Azadeh et al., 2016). Moreover, improvements programs at macro-ergonomics level are imperative for optimizing in organizations (Haydee et al., 2011).

It is concluded that the events that occur in systems arise from the way the partsengineered and human- fit system interact together. Mostly, the error and the consequent failures are both due to the attributes and the effects of many factors, such as bad workplace designs, complicated working processes, unstable workload, hazardous conditions, defective maintenance, uneven attention to production, unprofitable training, lack of motivation and empirical knowledge, non-responsive managerial systems, imperfect planning, non-adaptive organizational structures, inflexible job-based pay systems, random response systems, and unexpected environmental disruption (Meshkati, 1991).

The world is full of infinite resources and complexities as well as multiple conflicting goals; hence, safety is shaped through proactive resilient processes rather than through reactive hindrances and blockades (Woods and Hollnagel, 2006). The increase of complexity in highly technological systems, for instance, process industries leads to possibly calamitous failure styles and also new safety issues. Traditional risk assessment is inadequate for the risk evaluation that exists in the socio-technical system (Qureshi, 2008).

In socio-technical and complex systems, integrated resilience engineering (IRE) has become a significant field for safety management (Steen and Aven, 2011). Moreover, in large-scale and complex systems, some unanticipated conditions may happen, although risk management is fully carried out. From the resilience perspective, minimizing damages and decreasing compensations as well as getting operations back to normal status are priorities for operators when unexpected situations occur. In other words, resilience engineering helps recover system states after the occurrence of incidents instead of event avoidance. Since it is not possible to predict and prevent all threats, incident prevention is a subject of study in other process safety areas (e.g., risk assessment); hence, resilience is needed as an additional safety measure.

For many years, the concept of resilience has been investigated in non-chemical disciplines, such as biology, psychology, organizational science, computer science, and ecology and it has remained relatively undeveloped in manufacturing systems (Dinh et al, 
2012). It is supposed that the causation of events and accidents can be tracked to the organizational factors, functional performance variability, and the occurrence of unpredicted combinations (Shirali et al., 2012).

Recently, new notions have started to make a revolution in the safety of complex systems and the ways to improve and keep safety. These notions have also proposed a different new pattern that considers the positive contribution of people at all levels of the organization rather than considers only human errors (Huber et al., 2009).

Resilience engineering offers a new way of thinking about safety and accident; therefore, it has enticed extensive interest from industry and academic environment (Steen and Aven, 2011). This philosophy helps people become aware of ways to deal with the existing complexities in order to gain success (Costella et al., 2009). This is still a new notion and there are some vague and unanswered questions on how well it can stick to its promise (Madni and Jackson, 2009).

$\mathrm{RE}$ is a kind of safety attitude based on control and management of disturbances before, during, and after their incidence (Hollnagel et al., 2006). It is also associated with human factors, control theory, and safety engineering (Azadeh et al., 2015). RE concentrates on behaviors to reimburse for poor behavior, poor design, poor systems, and poor conditions (Furniss et al., 2011).

From an IRE perspective, a system that employs intrinsic human abilities in tune with engineered protections and organizational features is known as a resilient system. Consequently, this system will maximize the extent of a controlled manner both in expected and in unpredicted situations (Fujita, 2006).

In recent years, as resilience could be compatible with the performance and safety ideas rather than be methodically in conflict with them, it is regarded as a strategic notion that combats safety problems in complex organizations (Morel et al., 2009). In most organizations, performance assessment of human resources is a vital issue for supervisors, researchers, and decision-makers. DEA is one of the most renowned methods for evaluating the performance of workers in any organization. Some usages of DEA approach in engineering case studies are as follows: data mining (Kusiak and Tseng, 2000), optimization of power distribution unit (Azadeh et al., 2009), location optimization of wind plants (Azadeh et al., 2011) and performance assessment of IRE (Azadeh et al., 2014).

In this study, IRE framework is used. It comprises RE principles suggested by (Hollnagel et al., 2006) and four other items proposed by Azadeh et al. (2014). Thus, RE framework will be a subcategory of IRE (Azadeh and Salehi, 2014). The main objective of this study is to 
achieve more realistic results for decision makers in the fields of IRE and macro-ergonomics. Moreover, the effect of the suggested items is discussed in a quantitative form by using mathematical and statistical multivariate analysis methods, such as Data Envelopment Analysis (DEA), Fuzzy Data Envelopment, and Principal Component Analysis (PCA). It primarily intends to present a suitable design approach by considering IRE and macroergonomics factors. It can also help managers to identify the weaknesses and strengths of their system and, accordingly give suggestions for the improvement of the safety situation and system performance.

This study is organized as follows. Section 2 displays the proposed approach. Section 3 presents the methodology used in this study. Section 4 shows the application of the approach on a real case study. Concluding remarks are delivered in section 5.

\section{The proposed approach}

\subsection{Organizational design}

Organizational design can be defined as the design of an organization's work system structure and related processes to attain the organizational target. As stated by macro-ergonomic analysis of structure (MAS), the structure of a work system in many cases is imagined as having three core dimensions, namely complexity (differentiation and integration), formalization, and centralization (Stevenson, 1993; Bedeian and Zammuto, 1991; Robbins, 1983). In this study, the three organizational design indices are considered as follows:

- Formalization: From the viewpoint of macro-ergonomics, formalization is the degree to which jobs within a work system are standardized. Extremely formalized designs are considered by clear job descriptions, comprehensive rules, and obviously defined, standardized procedures covering work processes. Systems with a high level of formalization do not permit employees for high discretion over matters (Robbins, 1983). Moreover, low level of formalization in a system allows greater flexibility and lets for greater usage of employees' mental abilities. As a general rule, as jobs are simpler and more repetitive, the need for a higher level of formalization increases (Hendrick and Kleiner, 2002).

- Centralization: Centralization takes into consideration where formal decision making happens within the work system. In extremely centralized work systems, formal decision making is focused on a comparatively few number of individuals, groups, or levels, usually high in the organization. On the other hand, lower-level managers and employees have only negligible input into the decisions affecting their jobs (Robbins, 1983). In extremely decentralized work systems, decisions are deputized downward to the lowest level with the 
essential skills. Highly decentralized work systems, therefore, require lower-level employees to have a comparatively higher level of competence (Hendrick, 1997).

- Complexity: Complexity mentions the degree of differentiation and integration that exists in a work system structure. Differentiation discusses the degree that the work system is divided into parts. Integration argues the number and types of mechanisms designed within a work system for ensuring communication, coordination, and control among the differentiated components. Vertical, horizontal, and spatial differentiations are three prevalent types of differentiation. The increase of each of these items would result in increased work system complexity (Hendrick and Kleiner, 2002).

\subsection{Integrated resilience engineering}

IRE is an important field for safety management in socio-technical and complex systems. Consequently, considerable efforts have been made for the overview of features of resilient systems as well as for the development of concepts and the methods that can deliver a basic framework of IRE (Steen and Aven, 2011). This study considers the some items in order to increase the resilience level of complex systems and hazardous environments.

In this study, the six cornerstones of RE, proposed by Hollnagel et al. (2006), and four other indices, proposed by Azadeh et al. (2014), are considered as follows:

- Top Management commitment: Top-level management identifies the concerns and problems related to the human performance and attempts to take proper decisions in order to limit or eradicate them (Wreathall, 2006). Moreover, this factor is effective in safety issues of each system.

- Reporting culture: With a just reporting culture that is an atmosphere of trust, employees are stimulated to report crucial safety-related subjects (Reason, 1997). Without it, the ability of the organizations to learn from its weaknesses in defensive states will be limited (Wreathall, 2006).

- Learning: Not only IRE focuses on learning from the analysis of normal work, but also it emphasizes learning from accidents, incidents, and other happenings (Wreathall, 2006).

- Awareness: Management can become aware of matters, such as the events occurring in the organization, the quality of human performance, etc. through data gathering. Furthermore, employees should be aware of the current and desired states of defense systems (Wreathall, 2006). 
- Preparedness: It helps people prepare themselves to deal with the problems occuring in the system; hence, it can be a vital factor in giving quick response (Hollnagel et al., 2006).

- Flexibility: The flexibility attitude to RE is to design a more flexible process that can deal with unexpected events (Dinh et al., 2012).

- Self-organization: Identifying the efficient independent entities and giving them more authorities would lead to the distribution of authorities in organizations (Serugendo, 2009). In self-organized organizations, order comes from the activities of related operators who exchange information, do the jobs correctly, and unceasingly adapt to feedback about others' actions (Plowman et al., 2007).

- Teamwork: Teamwork can lessen individual and organizational pressures through shared support and staff's aid to each other when there is a high amount of system work (Azadeh et al., 2013). It helps systems gain cost-effective outcomes, decrease human errors, and increase system reliability. Therefore, it leads to the upgrading of safety (Xyrichis and Ream, 2008).

- Redundancy: Redundancy could have different meanings from different viewpoints. For instance, from an engineering perspective, it is believed that a copy of essential parts and basic equipment should exist in a manufacturing system to improve the system reliability (Frangopol and Curley, 1987). In human-machine systems, redundancy comes into play when two or more operators (people) are concerned with the completion of a required function and have access to the information related to that function (Clarke, 2005). This study has looked into this issue from two dimensions, including human and non-human perspectives (equipment, machinery, servers, and software).

- Fault-tolerant: Keeping the specified performance of a system constant regardless of the existence of errors is one of the key purposes of fault-tolerant (Ling and Duan, 2010). In other words, fault-tolerant makes it possible for the system to continue working under specific conditions with a limited or an unlimited amount of time in the case of shortage in one of the elements (machines, equipment, components, servers, software, and even human resources) (Azadeh et al., 2013).

\section{Methodology}

In this study, macro-ergonomics and IRE factors are evaluated by mathematical and statistical multivariate analyses, such as Data Envelopment Analysis (DEA) and Principal Component Analysis (PCA). Fuzzy DEA (FDEA) is also used in this research to decrease the 
uncertainty existing in qualitative indicators and human errors. In DEA approach, employees are considered as Decision Making Units (DMUs) while, in PCA, DMUs are the departments of the factory. The factory employees constitute the statistical population of the study. Figure 1 presents a schematic view of this approach. In summary, the proposed approach is achieved as follows:

Step 1: A standard questionnaire has been designed by considering the IRE and macroergonomics factors to evaluate the performance of the proposed ceramic and tile factory.

Step 2: Content validity of the test is performed based on the opinion of experts. If the results are acceptable, next step will be step 3. Otherwise, it is needed to go back to step 1.

Step 3: Gather necessary data. Employees must complete the standard questionnaire.

Step 4: Necessity for gathering more data

Step 5: Reliability test and factor analysis were conducted. If the results are acceptable, it is to go to step 6 in both approaches. Otherwise, it will be required to go back to step 4 .

\section{Approach 1:}

Step 6: Applied DEA and FDEA models

Step 7: Selection of the best $\alpha$-cut for FDEA based on Friedman or t-test

Step 8: Selection of DEA or FDEA model based on Friedman or $t$ test

Step 9: Determination of the optimum combination of macro-ergonomics factors through FDEA and Friedman test for delineating the best input and output variables

Step10: Performance of the sensitivity analysis. To do this, FDEA model is run by separately omitting indicators. Moreover, the applied mathematical modeling and Wilcoxon test or t-test are run.

Step 11: Description of the effectiveness of factors in system efficiency by omitting the selected factor and Wilcoxon or t-test.

Step 12: Computation of weight of each factor by calculating percentage changes in efficiency created by each factor.

Step 13: Verification and validation of step 12 by analysis of variance (ANOVA).

Step14: Determination of the optimum design approach based on integrated macroergonomics and resilience engineering in this tile and ceramic factory.

Approach 2:

Step 6: Ranking of the departments of this tile and ceramic factory by PCA and specification of the weaknesses and strengths of such systems.

Step 7: Verification and validation of PCA by NT. 


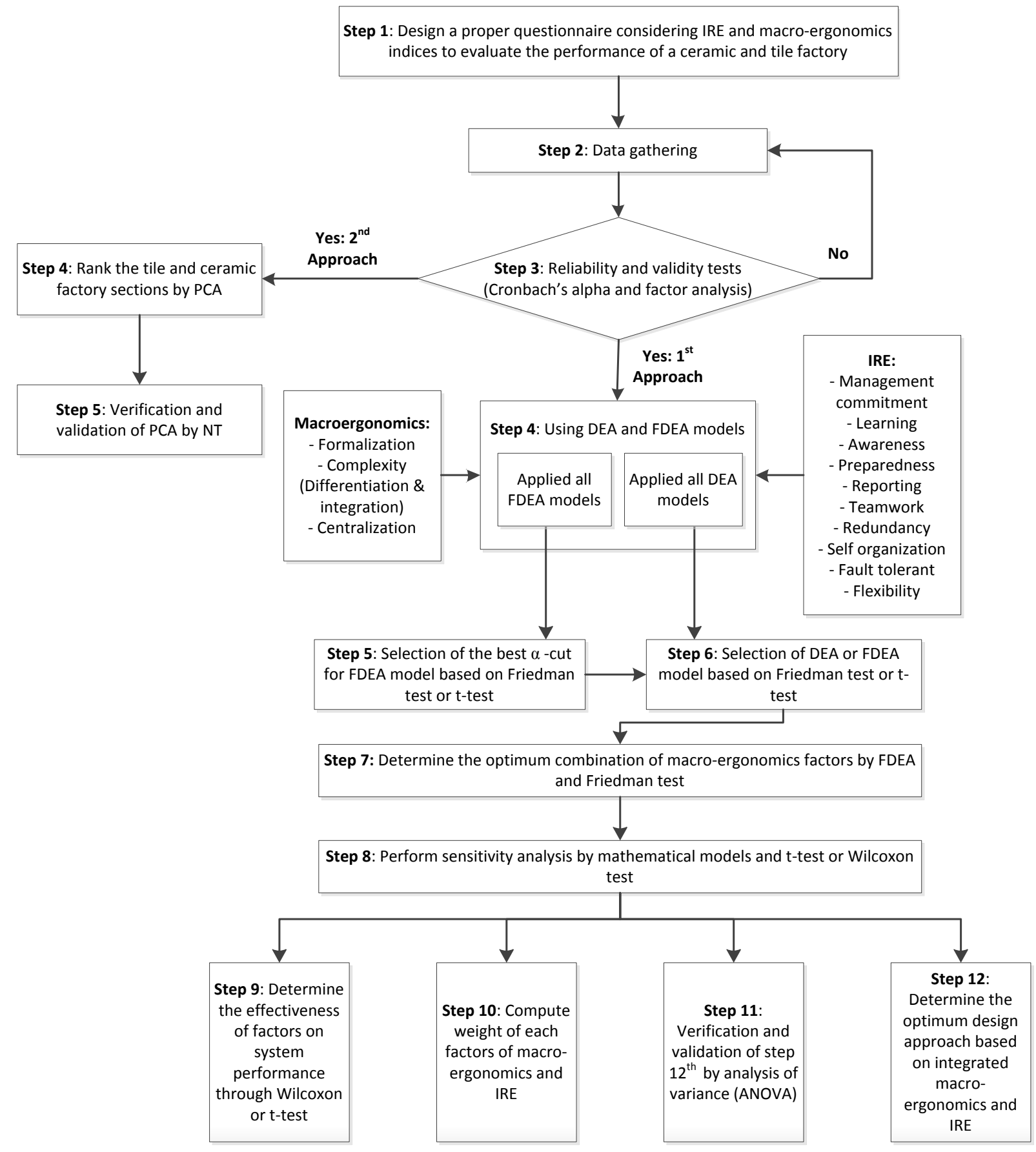

Figure 1: Schematic view of the proposed approach in this study

\subsection{DEA}

The linear programming system for the BCC output-oriented model is given in Model (1) (Charnes et al., 1978). This model assesses the relative efficiencies of $n$ DMUs $(j=1,2, \ldots, n)$ where each DMU contains $m$ inputs and $s$ outputs represented by $x_{1 j}, x_{2 j}, \ldots, x_{m j}$ and $y_{1 j}$, $\mathrm{y}_{2 \mathrm{j}}, \ldots, \mathrm{y}_{\mathrm{sj}}$, respectively. In the model, $\mathrm{x}_{\mathrm{ij}}$ shows value of $\mathrm{i}^{\text {th }}$ input for $\mathrm{j}^{\text {th }} \mathrm{DMU}$ and $\mathrm{y}_{\mathrm{rj}}$ shows value of $\mathrm{r}^{\text {th }}$ output for $\mathrm{j}^{\text {th }}$ DMU. $\theta$ indicates efficiency score for DMU under study and $\mathrm{x}_{\mathrm{i} 0}$ and 
$\mathrm{y}_{\mathrm{r} 0}$ shows input and output of DMU under study respectively. In addition, $\lambda$ is a vector assigned to individual productive units.

$\operatorname{Max} \theta$,

s.t. $x_{i 0} \geq \sum_{j=1}^{85} \lambda_{j} x_{i j}, i=1, \ldots, 4$

$\theta y_{r 0} \leq \sum_{j=1}^{85} \lambda_{j} y_{r j}, r=1, \ldots, 12 \quad$ Model (1)

$\sum_{j=1}^{85} \lambda_{j}=1$

$\lambda_{\mathrm{j}} \geq 0, \mathrm{j}=1, \ldots, 85$

Original DEA model was adjusted by Andersen and Petersen for DEA-based ranking purposes to rank efficient units because it not capable of ranking efficient units (Andersen \& Petersen, 1993). They suggested a model for ranking the efficient units that permitted the determination of the most efficient unit. In this method, the score pertaining to the efficient units can be above 1; therefore, it allows the ranking of efficient units just as inefficient units. Efficient units are ranked through the following:

$\operatorname{Miny}_{0}=\theta-\varepsilon\left(\sum_{i=1}^{m} s_{i}^{-}+\sum_{r=1}^{s} s_{r}^{+}\right)$

s.t.

$\sum_{j=1}^{n} \lambda_{j} x_{i j}+s_{i}^{-}=\theta x_{i 0}, j \neq 0 \quad$ Model (2)

$\sum_{j=1}^{n} \lambda_{j} y_{r j}-s_{r}^{+}=y_{r 0}$

$\lambda_{j}, s_{i}^{-}, s_{r}^{+} \geq 0 \forall j, r, i$

In the above models, $s_{\mathrm{i}}^{-}$and $\mathrm{s}_{\mathrm{r}}^{+}$are vectors of addition input and output variables.

\subsection{Fuzzy Data Envelopment Analysis (FDEA)}

Fuzzy DEA appears to be suitable for the problems associated with the uncertainty relevant to the available qualitative data set. This is due to the fact that most of the indicators for DMUs have a non-crisp nature and are critical. Thus, fuzzy DEA, which uses the 
principle of fuzzy sets to demonstrate uncertain data and examine them more precisely for performance assessment under undefined conditions, is used.

Saati et al. (2002) suggested a fuzzy form of DEA using triangular fuzzy numbers by inserting $\tilde{x}_{i j}=\left(x_{i j}^{m}, x_{i j}^{l}, x_{i j}^{u}\right)$ and $\tilde{y}_{i j}=\left(y_{i j}^{m}, y_{i j}^{l}, y_{i j}^{u}\right)$ into the model. In this study, triangular fuzzy numbers also constitute the inputs and outputs of the problem. Thus, there is a model with fuzzy parameters that are presented in Model (3).

$\operatorname{Max} Z=\sum_{r=1}^{12} u_{r} y_{r 0}-u_{0}$

s.t.

$\sum_{i=1}^{4} v_{i} x_{i 0}=1$

Model (3)

$\sum_{r=1}^{12} u_{r} y_{r j}-\sum_{i=1}^{4} v_{i} x_{i j}-u_{0} \leq 0, j=1, \ldots, 85, j \neq 0$

$u_{r} \geq 0, r=1, \ldots, 12$

$v_{i} \geq 0, i=1, \ldots, 4$

To solve this model, we should convert it to a linear programming model formation. To this end, the probabilistic programming approach introduced by Kosko (1986) is used. The final linear programming construction of fuzzy DEA model is represented as Model (4).

$\operatorname{Max}\left\{\sum_{r=1}^{12}\left(\left(\left(\left(y_{r 0}^{l}+2 y_{r 0}^{m}+y_{r 0}^{u}\right) / 4\right) * \mathrm{u}_{r}\right)-u_{0}\right\}\right.$

s.t.

Model (4)

$$
\begin{aligned}
& \sum_{i=1}^{4}\left(\left[(1-\alpha / 2) *\left(\left(x_{i j}^{m}+x_{i j}^{u}\right) / 2\right)+(\alpha / 2)\left(\left(x_{x i j}^{m}+x_{i j}^{l}\right) / 2\right] * v_{i}\right) \leq 1\right. \\
& \sum_{r=1}^{12}\left(\left[(1-\alpha / 2) *\left(\left(\mathrm{y}_{r j}^{m}+y_{r j}^{u}\right) / 2\right)+(\alpha / 2)\left(\left(\mathrm{y}_{r j}^{m}+y_{r j}^{l}\right) / 2\right]^{*} \mathrm{u}_{r}\right) \leq 1\right. \\
& \sum_{r=1}^{12}\left(\left[(1-\alpha) *\left(\left(\mathrm{y}_{r j}^{m}+y_{r j}^{u}\right) / 2\right)+\alpha\left(\left(\mathrm{y}_{r j}^{m}+y_{r j}^{l}\right) / 2\right]^{*} \mathrm{u}_{r}\right)\right. \\
& -\sum_{i=1}^{4}\left(\left[(1-\alpha) *\left(\left(x_{i j}^{m}+x_{i j}^{u}\right) / 2\right)+\alpha\left(\left(x_{x i j}^{m}+x_{i j}^{l}\right) / 2\right] * v_{i}\right)-u_{0} \leq 0\right.
\end{aligned}
$$

$u_{r} \geq \varepsilon, \quad \mathrm{r}=1, . ., 12$

$v_{i} \geq \varepsilon, \mathrm{i}=1, . ., 4$ 


\subsection{PCA}

Principal component analysis (PCA) is a statistical procedure that can be used in multivariate statistics, such as factor analysis. PCA is a data reduction method. It reduces the number of variables without losing the key information of the problem (Bolch and Huang, 1974). Moreover, PCA is a method for evaluating the efficiency and ranking the DMUs. In other words, it is a popular ranking method in multidimensional analysis (Slottje et al., 1991).

\subsection{Numerical Taxonomy (NT)}

Numerical taxonomy (NT) is a method which is used for recognizing homogeneous from non-homogeneous items. It is also capable of ranking decision making units (DMUs) in a special group (Azadeh et al., 2007). Moreover, NT approach is able to divide a group of DMUs to homogenous sub-groups based on given factors (Shirali et al., 2013).

\section{Case study: a Tile and Ceramic factory}

The experiment is conducted in Pardis Ceram, a tile and ceramic factory in North East of Iran. The plant is founded in 2012 with more than 700 employees. Moreover, nearly 60 Chinese technicians are working in this factory. As mentioned before, 85 operators from different departments, including glaze, trading, accounting, packing, maintenance, loading, raw material, quality control, warehouse, printing and furnace participated in this study. Performance of these operators and, hence, the system performance are evaluated by considering IRE and macro-ergonomics factors through DEA and PCA. In this case study, DEA and FDEA models are applied to determine the optimum design approach for this factory. In addition, IRE factors are considered as output variables for this model. This study specifies the optimum combination of macro-ergonomics factors through mathematical modeling for the purpose of choosing the best mixture of input variables.

\subsection{Data gathering}

The questionnaire, designed in previous steps, was completed by operators of different departments. The respondents could select a value among 1-10 to give response to the questionnaire items wherein 1 was defined as the lowest value and 10 as the highest value in relation to performance of their department.

\subsection{Reliability and validity tests on questionnaire}


The data obtained from the questionnaire were analyzed, reliability test and factor analysis were conducted using statistical package for social science (SPSS) that is a software package used for logical batched and non-batched statistical analysis. In this study, SPSS version 18 was used. The reliability of the collected data was measured through Cronbach's alpha. The values of Cronbach's alpha for each group are presented in Table 1 that the values are quite acceptable. Content validity, which is not quantitative, was used based on the judgment of experts of the field. In addition the construct validity of the questionnaire was performed using factor analysis. An Eigen value higher than one for any group specified that the questions within each group matched on one factor and approved the correctness of each question in measuring a factor (Hair et al., 1998; Olson et al., 2005). The questions were placed in groups in such a way that a desired Cronbach's alpha and Eigen value were recognized. Results of reliability and validity analysis are shown in Table 1. In the table, component indicates the number of questions related to each factor and component loading represents how much a factor explains a variable in factor analysis.

In this study, 11 departments were asked to answer the questionnaire. The name of the departments and the number of respondents are shown in Table 2.

\section{Table 1}

Results of reliability and validity analysis

\begin{tabular}{|c|c|c|c|}
\hline \multirow[t]{2}{*}{ Group type } & \multirow{2}{*}{$\begin{array}{c}\text { Reliability } \\
\text { (Cronbach's } \\
\text { alpha) }\end{array}$} & \multicolumn{2}{|c|}{ Factor analysis } \\
\hline & & Component & $\begin{array}{c}\text { Component } \\
\text { (factor) loading }\end{array}$ \\
\hline \multirow{9}{*}{ Formalization } & \multirow{9}{*}{0.861} & 1 & .921 \\
\hline & & 2 & .791 \\
\hline & & 3 & .861 \\
\hline & & 4 & .809 \\
\hline & & 5 & .816 \\
\hline & & 6 & .773 \\
\hline & & 7 & .827 \\
\hline & & 8 & .776 \\
\hline & & 9 & .841 \\
\hline \multirow{4}{*}{ Centralization } & \multirow{4}{*}{0.812} & 1 & .901 \\
\hline & & 2 & .707 \\
\hline & & 3 & .733 \\
\hline & & 4 & .751 \\
\hline \multirow{7}{*}{ Complexity } & \multirow{7}{*}{0.847} & 1 & .863 \\
\hline & & 2 & .753 \\
\hline & & 3 & .720 \\
\hline & & 4 & .704 \\
\hline & & 5 & .825 \\
\hline & & 6 & .721 \\
\hline & & 7 & .736 \\
\hline
\end{tabular}




\begin{tabular}{|c|c|c|c|}
\hline \multirow{4}{*}{ Management Commitment } & \multirow{4}{*}{0.873} & 1 & .491 \\
\hline & & 2 & .473 \\
\hline & & 3 & .579 \\
\hline & & 4 & .551 \\
\hline \multirow{5}{*}{ Learning } & \multirow{5}{*}{0.918} & 1 & .748 \\
\hline & & 2 & .669 \\
\hline & & 3 & .648 \\
\hline & & 4 & .633 \\
\hline & & 5 & .669 \\
\hline \multirow{3}{*}{ Awareness } & \multirow{3}{*}{0.769} & 1 & .559 \\
\hline & & 2 & .499 \\
\hline & & 3 & .426 \\
\hline \multirow{3}{*}{ Reporting Culture } & \multirow{3}{*}{0.869} & 1 & .904 \\
\hline & & 2 & .827 \\
\hline & & 3 & .811 \\
\hline \multirow{3}{*}{ Flexibility } & \multirow{3}{*}{0.887} & 1 & .885 \\
\hline & & 2 & .824 \\
\hline & & 3 & .820 \\
\hline \multirow{2}{*}{ Self-organization } & \multirow{2}{*}{0.812} & 1 & .568 \\
\hline & & 2 & .530 \\
\hline \multirow{2}{*}{ Redundancy } & \multirow{2}{*}{0.884} & 1 & .712 \\
\hline & & 2 & .761 \\
\hline \multirow{3}{*}{ Preparedness } & \multirow{3}{*}{0.839} & 1 & .562 \\
\hline & & 2 & .597 \\
\hline & & 3 & .590 \\
\hline \multirow{2}{*}{ Fault tolerant } & \multirow{2}{*}{0.783} & 1 & .427 \\
\hline & & 2 & .414 \\
\hline \multirow{3}{*}{ Teamwork } & \multirow{3}{*}{0.821} & 1 & .443 \\
\hline & & 2 & .426 \\
\hline & & 3 & .487 \\
\hline
\end{tabular}

\section{Table 2}

DMUs' name and number of respondents in this study

\begin{tabular}{|l|l|l|l|}
\hline Department name & Type of personnel & Number of respondents & DMUs number \\
\hline Glaze & operators & 8 & DMU 1 \\
\hline Trading & operators & 7 & DMU 2 \\
\hline Accounting & operators & 9 & DMU 3 \\
\hline packing & operators & 16 & DMU 4 \\
\hline Maintenance & operators & 5 & DMU 5 \\
\hline Loading & operators & 6 & DMU 6 \\
\hline Raw material & operators & 8 & DMU 7 \\
\hline QC(Quality Control) & operators & 4 & DMU 8 \\
\hline Warehouse & operators & 7 & DMU 9 \\
\hline Printing & operators & 9 & DMU 10 \\
\hline Furnace & operators & 6 & DMU 11 \\
\hline
\end{tabular}

DMU: decision-making unit 


\subsection{Results of DEA and FDEA}

To decrease the uncertainty existing in qualitative indicators and human error, fuzzy DEA model is used for a number of $\alpha$-cuts using triangular fuzzy numbers. In this study, all IRE factors should desirably increase, so these factors are considered as outputs, but about macro-ergonomics indices it cannot be conclusively decided which decision is better, whether decrease or increase. In other words, in this particular case study, it is not obvious which factors of macro-ergonomics should be considered as input and which one as output. Therefore, to solve this enigma, 8 scenarios were defined and by Friedman test, a mathematical modeling, would determine the best $\alpha$-cut and the most precise model between DEA and FDEA and, finally, the best combination of macro-ergonomics factors is determined as input variables.

The 8 scenarios are shown in Table 3 as follows:

\begin{tabular}{|c|c|c|}
\hline $\begin{array}{l}\text { Table } 3 \\
\text { The possible } \\
\text { proper input }\end{array}$ & $\begin{array}{l}\text { enarios for choosing the best combination of ma } \\
\text { riables in this particular case study }\end{array}$ & gonomics factors to determine the \\
\hline Scenarios & Inputs & Outputs \\
\hline 1 & Demographics + Centralization & IRE + Complexity + Formalization \\
\hline 2 & Demographics + Formalization & IRE + Complexity + Centralization \\
\hline 3 & Demographics + Complexity & IRE + Formalization + Centralization \\
\hline 4 & Demographics + Complexity + Centralization & IRE+ Formalization \\
\hline 5 & Demographics +Formalization +Centralization & IRE+ Complexity \\
\hline 6 & Demographics +Complexity + Formalization & IRE+ Centralization \\
\hline 7 & Demographics +All Macro-ergonomics factors & IRE \\
\hline 8 & Demographics & IRE+ All Macro-ergonomics factors \\
\hline
\end{tabular}

The final results for selecting the best $\alpha$-cut and the most accurate model between DEA and FDEA and, finally, the determination of the best combination of macro-ergonomics factors as input variables through Friedman test are shown in Table 4,5,6.

Table 4 just shows part and final results of Friedman test. Alpha level of 0.1 in BCC output oriented model in all scenarios except scenario 8 is known as the best $\alpha$-cut and model by Friedman ranking. 
Moreover, in scenario 8 , the best $\alpha$-cut is 0.01 in BCC output oriented model. Then, with Friedman test, the best $\alpha$-cut in all scenarios was chosen. The results are shown in Table 5 as follows:

\begin{tabular}{|c|c|c|c|c|c|c|c|c|}
\hline \multicolumn{9}{|c|}{$\begin{array}{l}\text { Table } 4 \\
\text { Friedman Ranks }\end{array}$} \\
\hline Scenarios & 1 & 2 & 3 & 4 & 5 & 6 & 7 & 8 \\
\hline $\begin{array}{c}\text { ВCC OO } \\
\alpha-\text { cut }=0.01\end{array}$ & 24.26 & 25.68 & 29.89 & 28.16 & 29.11 & 21.79 & 22.67 & 44.59 \\
\hline $\begin{array}{c}\text { BCC OO } \\
\alpha-\operatorname{cut}=0.1\end{array}$ & 36.73 & 37.93 & 40.07 & 34.89 & 37.41 & 40.76 & 39.96 & 15.74 \\
\hline
\end{tabular}

\begin{tabular}{|l|l|}
\hline $\begin{array}{l}\text { Table 5 } \\
\text { Choosing the best } \alpha \text {-cut in all scenarios }\end{array}$ \\
\hline Scenarios & Mean Rank (Friedman test) \\
\hline 1 & 4.24 \\
\hline 2 & 4.69 \\
\hline 3 & 5.66 \\
\hline 4 & 3.19 \\
\hline 5 & 3.86 \\
\hline 6 & 5.07 \\
\hline 7 & 4.79 \\
\hline 8 & 4.51 \\
\hline
\end{tabular}

As it is illustrated in Table 5, the most competent model and the best $\alpha$-cut are BCC output-oriented and alpha of 0.1 in Scenario 3. To determine the optimum model between DEA and FDEA, Friedman test is employed. The results are described in Table 6.

\section{Table 6}

Choosing the optimum model.

\begin{tabular}{|l|l|}
\hline Model & Mean Rank (Friedman test) \\
\hline DEA & 1.13 \\
\hline FDEA & 1.87 \\
\hline
\end{tabular}


The results of Table 6 may lead one to conclude that fuzzy DEA model is the best and the most precise model due to the uncertainty existing in qualitative indicators.

In this research, output-oriented FDEA with 4 input factors and 12 output factors is used. Then, Auto Assess ${ }^{\circledR}$ software was employed to measure the efficiency of 85 employees of the tile and ceramic factory as decision making units, each having $\mathrm{m}$ inputs $(\mathrm{m}=4)$ and $\mathrm{s}$ outputs ( $=12$ ) (Azadeh, 2007).

Input and output factors are:

Inputs

1.Complexity

2.Age

3. Education

4.Job experience

\section{Outputs}

1.Formalization

2.Centralization

3.Management Commitment

4.Learning

5.Awareness

6.Flexibility

7.Preparedness

8.Reporting Culture

9.Fault tolerant

10.Selforganization

11.Redundancy

12. Teamwork

\subsection{Sensitivity analysis}

To identify the impact of IRE and macro-ergonomics factors in this tile and ceramic factory and also determine the optimum design approach for this particular case study, sensitivity analysis was performed. FDEA model, carefully chosen in previous steps, has been run 16 times. In every single run, one factor must be removed. Table 7 shows the final results of this analysis. As it can be seen in Table 7, 1.059 represents the average efficiency score for each DMU when centralization is removed from the factor list. Other results have been similarly obtained.

\section{Table 7}

Results of sensitivity analysis for each factor

\begin{tabular}{|c|c|c|c|}
\hline Factors & $\begin{array}{l}\text { Technical Efficiency in } \\
\text { absence of each factor }\end{array}$ & Factors & $\begin{array}{c}\text { Technical Efficiency in } \\
\text { absence of each factor }\end{array}$ \\
\hline Centralization & 1.059 & Preparedness & 1.039 \\
\hline Complexity & 1.020 & Redundancy & 1.060 \\
\hline
\end{tabular}




\begin{tabular}{|c|c|c|c|}
\hline Formalization & 1.034 & Reporting & 1.068 \\
\hline Awareness & 1.064 & Self- organization & 1.045 \\
\hline Commitment & 1.049 & Teamwork & 1.061 \\
\hline Fault- tolerant & 1.059 & Job experience & 1.058 \\
\hline Flexibility & 1.061 & Age & 1.070 \\
\hline Learning & 1.003 & Education & 1.064 \\
\hline
\end{tabular}

Wilcoxon and paired samples t-test were used in order to see if the factor elimination has a significant effect or to determine if there is a significant change in average efficiency of factors, before and after their elimination in this particular case study (identifying the effectiveness of each factor in system efficiency of the proposed case study).The results are shown in Table 8 . The hypothesis testing is as follows:

Null Hypothesis (H0):

Assumes no difference, association or relationship between the variables

Alternative Hypothesis (H1):

Assumes a significant difference, association or relationship between the variables

[If $\mathrm{p} \leq 0.05$, reject $\mathrm{H} 0$ in favor of $\mathrm{H} 1$ and if $\mathrm{p}>0.05$, fail to reject $\mathrm{H} 0$ ].

$\mu_{\mathrm{i}}$ : the average of efficiencies after eliminating factor $\mathrm{i}$

$\mu_{\mathrm{f}}$ : the average of efficiencies when all factors are present

It is possible to conclude from the results of Table 8 that there is a significant difference between all factors since all the aforementioned factors have a P-value less than 0.05 . It means that there is a difference between the mean scores of efficiencies factors before and after their elimination. Similarly, it is obvious that the average efficiency of each removed factor is less than the total average efficiency as shown in Table 8.

Table 9 shows the average efficiency for each eliminated factor compared to the situation which all factors are present. In fact, the situation including all factors is shown as no eliminated factor in Table 9. The difference between total average efficiency, computed by 16 factors, and average efficiency of each omitted factor are calculated. Table 9 shows these differences. As it is seen in Table 9, the elimination of learning, complexity, formalization, and preparedness have the greatest effect on average efficiency, respectively. Hence, these factors are introduced as important factors in this specific case study through sensitivity analysis. Planning for the improvement of these factors can enhance the performance of this factory.

\section{Table 8}

Paired t-test and Wilcoxon test results 


\begin{tabular}{|c|c|c|c|c|}
\hline Factors/Test & $\begin{array}{c}\text { Wilcoxon Test } \\
\text { (P-value) }\end{array}$ & $\begin{array}{c}\text { Paired t-test } \\
\text { (P-value) }\end{array}$ & Mean & Result \\
\hline Full Factor & - & - & 1.071 & - \\
\hline Centralization & 0.000 & 0.006 & 1.059 & $\mu_{\mathrm{i}}<\mu_{\mathrm{f}}$ \\
\hline Complexity & 0.000 & 0.000 & 1.020 & $\mu_{\mathrm{i}}<\mu_{\mathrm{f}}$ \\
\hline Formalization & 0.000 & 0.000 & 1.034 & $\mu_{\mathrm{i}}<\mu_{\mathrm{f}}$ \\
\hline Awareness & 0.001 & 0.000 & 1.064 & $\mu_{\mathrm{i}}<\mu_{\mathrm{f}}$ \\
\hline Commitment management & 0.000 & 0.000 & 1.049 & $\mu_{\mathrm{i}}<\mu_{\mathrm{f}}$ \\
\hline Fault-tolerant & 0.000 & 0.001 & 1.057 & $\mu_{\mathrm{i}}<\mu_{\mathrm{f}}$ \\
\hline Flexibility & 0.003 & 0.024 & 1.061 & $\mu_{\mathrm{i}}<\mu_{\mathrm{f}}$ \\
\hline Learning & 0.000 & 0.000 & 1.003 & $\mu_{\mathrm{i}}<\mu_{\mathrm{f}}$ \\
\hline Preparedness & 0.000 & 0.000 & 1.039 & $\mu_{\mathrm{i}}<\mu_{\mathrm{f}}$ \\
\hline Redundancy & 0.000 & 0.022 & 1.060 & $\mu_{\mathrm{i}}<\mu_{\mathrm{f}}$ \\
\hline Reporting & 0.050 & 0.050 & 1.068 & $\mu_{\mathrm{i}}<\mu_{\mathrm{f}}$ \\
\hline Self-organization & 0.000 & 0.000 & 1.045 & $\mu_{\mathrm{i}}<\mu_{\mathrm{f}}$ \\
\hline
\end{tabular}

\section{Table 9}

Difference between average efficiency before and after factor elimination

\begin{tabular}{|c|c|c|}
\hline Eliminated factor & $\begin{array}{c}\text { Average } \\
\text { Efficiency }\end{array}$ & Mean Difference $(\boldsymbol{\mu f} \boldsymbol{\mu} \boldsymbol{\mu i})$ \\
\hline Full Factor (No eliminated factors) & 1.071 & - \\
\hline Centralization & 1.059 & 0.012 \\
\hline Complexity & 1.020 & 0.051 \\
\hline Formalization & 1.034 & 0.037 \\
\hline Awareness & 1.064 & 0.007 \\
\hline Commitment management & 1.049 & 0.022 \\
\hline Fault-tolerant & 1.057 & 0.014 \\
\hline Flexibility & 1.061 & 0.010 \\
\hline Learning & 1.003 & 0.068 \\
\hline
\end{tabular}




\begin{tabular}{|c|c|c|}
\hline Preparedness & 1.039 & 0.032 \\
\hline Redundancy & 1.060 & 0.011 \\
\hline Reporting & 1.068 & 0.003 \\
\hline Self-organization & 1.045 & 0.026 \\
\hline Team work & 1.061 & 0.010 \\
\hline Job experience & 1.058 & 0.013 \\
\hline Age & 1.070 & 0.001 \\
\hline Education & 1.064 & 0.007 \\
\hline
\end{tabular}

\subsection{Calculation of weight factors}

In this section, the weight of each resilience and macro-ergonomics factor is calculated based on the results of sensitivity analysis. These weights are calculated by percentage of change in efficiency score, which is created by each factor (see Table 9). Weight of each factor for this particular case study is illustrated in Figure 2. As it is shown in Figure 2, learning, complexity, formalization, and preparedness have the greatest weight in comparison to other indices. Weight of learning is 21.1 percent, which shows the importance of this factor in performance efficiency of this factory. The weight percentage and their rank are shown in Table 10.

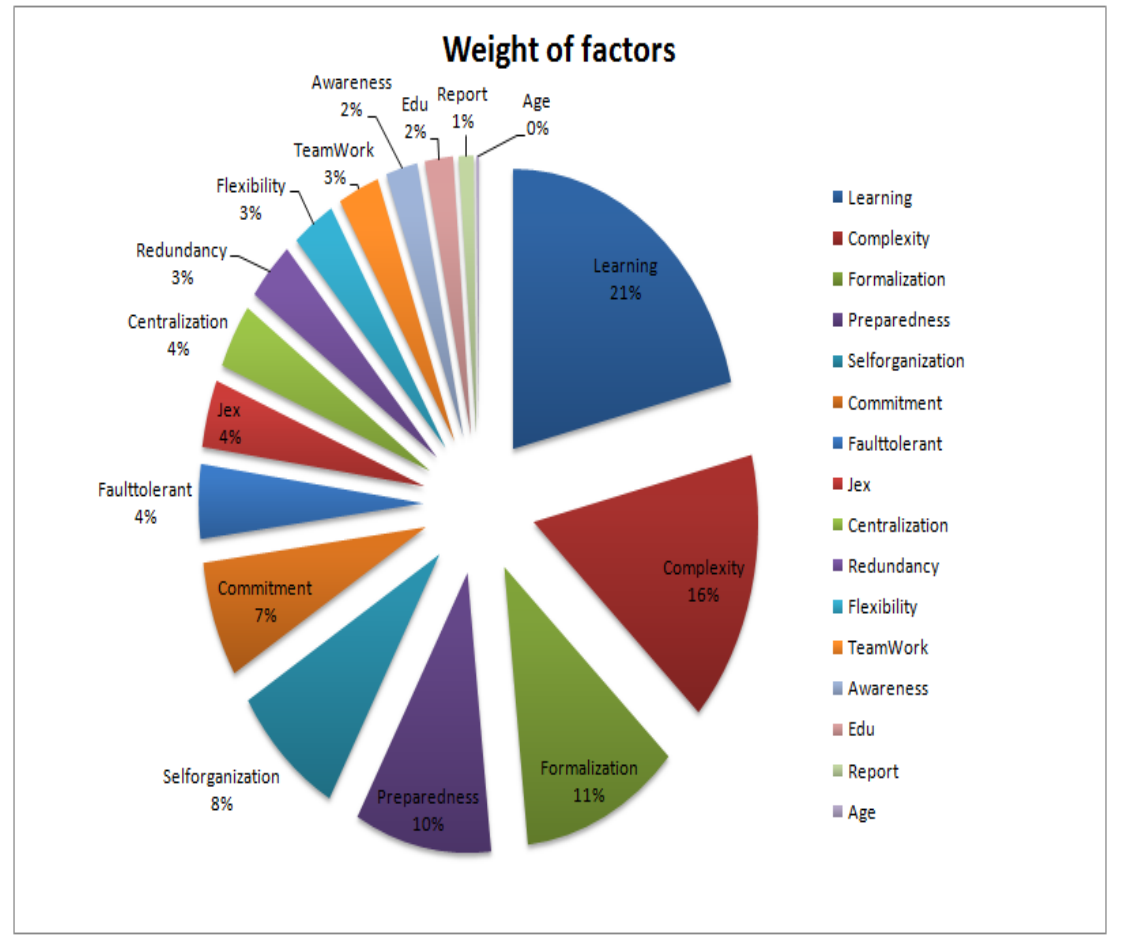

Figure 2: Weight of each IRE and macro-ergonomics factors in performance efficiency 


\begin{tabular}{|c|c|c|}
\hline $\begin{array}{l}\text { Table 10 } \\
\text { Weight of IRE and macro-ergonomics factors }\end{array}$ \\
\hline Factor & Weight & Rank \\
\hline Learning & $21.1 \%$ & 1 \\
\hline Complexity & $15.7 \%$ & 2 \\
\hline Formalization & $11.4 \%$ & 3 \\
\hline Preparedness & $9.8 \%$ & 4 \\
\hline Self-organization & $8.1 \%$ & 5 \\
\hline Commitment & $6.7 \%$ & 6 \\
\hline Fault tolerant & $4.3 \%$ & 7 \\
\hline Job Experience & $3.9 \%$ & 8 \\
\hline Centralization & $3.8 \%$ & 9 \\
\hline Redundancy & $3.5 \%$ & 10 \\
\hline Flexibility & $3.1 \%$ & 11 \\
\hline Team Work & $3.0 \%$ & 12 \\
\hline Awareness & $2.3 \%$ & 13 \\
\hline Education & $2.0 \%$ & 14 \\
\hline Report & $1.1 \%$ & 15 \\
\hline Age & $0.2 \%$ & 16 \\
\hline
\end{tabular}

\subsection{ANOVA and LSD Experiments}

In this section, analysis of variance (ANOVA) is employed to verify and validate the results related to the previous step. ANOVA is a statistical method used to test differences in the mean score between two or more groups or variables. In other words, it is used to determine whether there is any significant difference between the means of three or more independent groups. To determine which specific groups differed from each other, LSD test is used. This test can compare mean of each group by pairwise comparisons. This method can be applied if only the null hypothesis (H0) is rejected in ANOVA test and there is a significant difference among the means of groups.

In this study, ANOVA test was done by SPSS software and the results revealed that $\mathrm{p}$ value ( significance $=0)$ is less than significance level $(\alpha=0.05)$. Hence, the null hypothesis (H0) is rejected. This shows that at least one group differs from the other groups. Therefore, the Least Significant Difference (LSD) test was used. The Least Significant Difference (LSD) test is employed in the context of the analysis of variance, when the F-ratio suggests rejection 
of the null hypothesis $\mathrm{H} 0$, that is, when the difference between the population means is significant.

\subsection{Sensitivity analysis for IRE and macro-ergonomics approaches}

In the next section, the effect of macro-ergonomics and IRE indices is separately demonstrated in this particular tile and ceramic factory. For this purpose, sensitivity analysis is applied. The influential indices are recognized using this analysis. This can help managers and decision makers recommend the appropriate strategies by concentrating on substantial factors. Therefore, the optimum design approach for this particular case study can be determined (macro-ergonomics, IRE or combination of these two concepts).

Additionally, the results of sensitivity analysis can demonstrate the role of each IRE and macro-ergonomics concept in performance improvement. Furthermore, this analysis can be useful in complex systems, such as tile and ceramic factory to enhance performance with respect to important indices. Doing so, FDEA model has been run twice with IRE and macroergonomics outputs, separately. Average technical efficiency for each DMU is displayed in Table 11 column 2 by taking into consideration IRE factors and ignoring macro-ergonomics. In fact, in this part, only IRE factors are considered as outputs and FDEA model is run by considering 3 inputs and 10 outputs. In the same way, average technical efficiency for each DMU is shown in Table 11, column 3 by considering macro-ergonomics factors and ignoring IRE factors. In this step, only macro-ergonomics factors are considered as outputs and FDEA model is run by considering 4 inputs and 2 outputs. The results of sensitivity analysis are depicted in Table 11.

Average technical efficiency with respect to macro-ergonomics and IRE criteria is shown in Figure 3, separately. Moreover, the importance of each concept is illustrated in Figure 4.

In the company with the results in previous steps as in Figure 3 and Table 12, IRE factors are more effective than macro-ergonomics factors in reducing average efficiencies of DMUs. Therefore, IRE factors have the greatest influence on efficiency scores. This category can play a key role in management decisions.

The identification of the noteworthy IRE indicators is indispensable for continuous performance improvement.

The change percentage in the efficiency scores created by the omission of each indicator is illustrated in Figure 5. As it is seen in Figure 5, "learning" and "preparedness" have the least average value of efficiency in this factory and must be improved by decision makers. 
Moreover, the importance of each macro-ergonomic indicator in this particular case study is illustrated in Figure 6.

Table 11

Average technical efficiency of DMUs by considering RE and macro-ergonomics factors separately

\begin{tabular}{|c|c|c|}
\hline $\begin{array}{c}\text { Average total technical } \\
\text { efficiency }\end{array}$ & $\begin{array}{c}\text { Average technical efficiency } \\
\text { in absence of macro- } \\
\text { ergonomics }\end{array}$ & $\begin{array}{c}\text { Average technical efficiency } \\
\text { in absence of IRE }\end{array}$ \\
\hline 1.071 & 1.008 & 0.925 \\
\hline
\end{tabular}

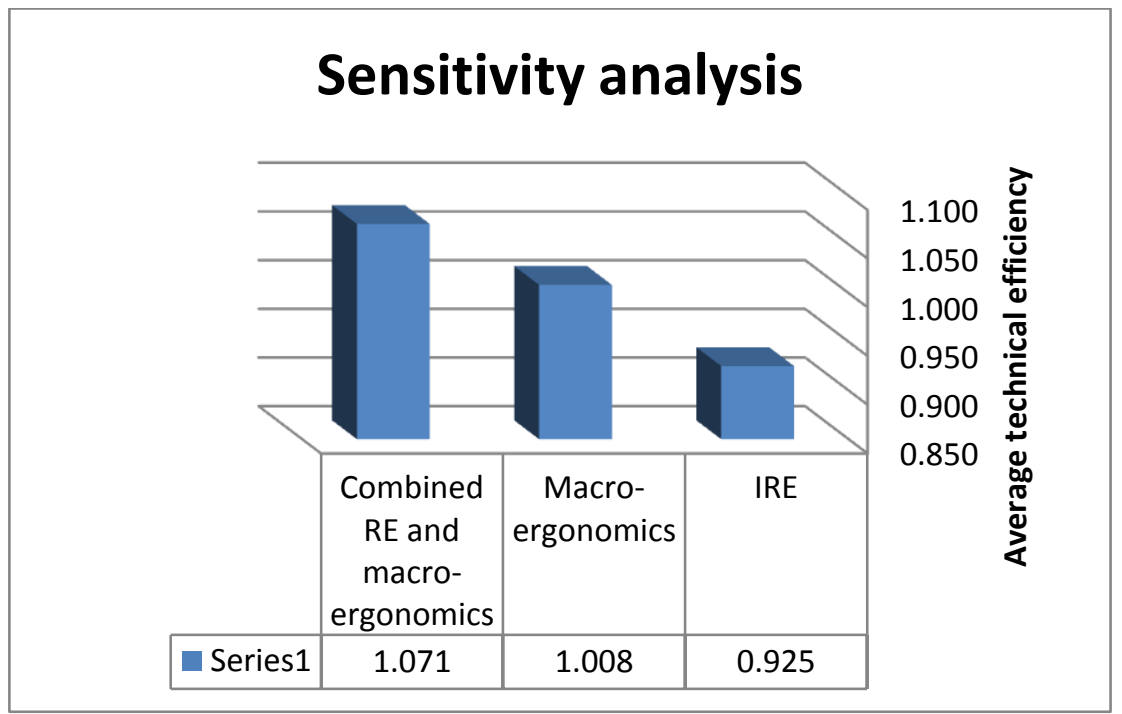

Figure 3: Sensitivity analysis results

Table 12

Sensitivity analysis results

\begin{tabular}{|c|c|c|c|c|c|c|}
\hline Factors/Test & $\begin{array}{c}\text { Wilcoxon } \\
\text { test }\end{array}$ & t-test & $\begin{array}{c}\text { Average } \\
\text { Efficiency }\end{array}$ & Result & $\begin{array}{c}\text { Mean } \\
\text { Difference } \\
(\boldsymbol{\mu f}-\mu \mathrm{i})\end{array}$ & Weight of factor \\
\hline Full Factor & - & & 1.071 & - & & - \\
\hline IRE & 0.000 & 0.000 & 0.925 & $\mu \mathrm{i}<\mu \mathrm{f}$ & 0.146 & $69.8 \%$ \\
\hline Macro-ergonomics & 0.001 & 0.000 & 1.008 & $\mu \mathrm{i}<\mu \mathrm{f}$ & 0.063 & $30.2 \%$ \\
\hline
\end{tabular}




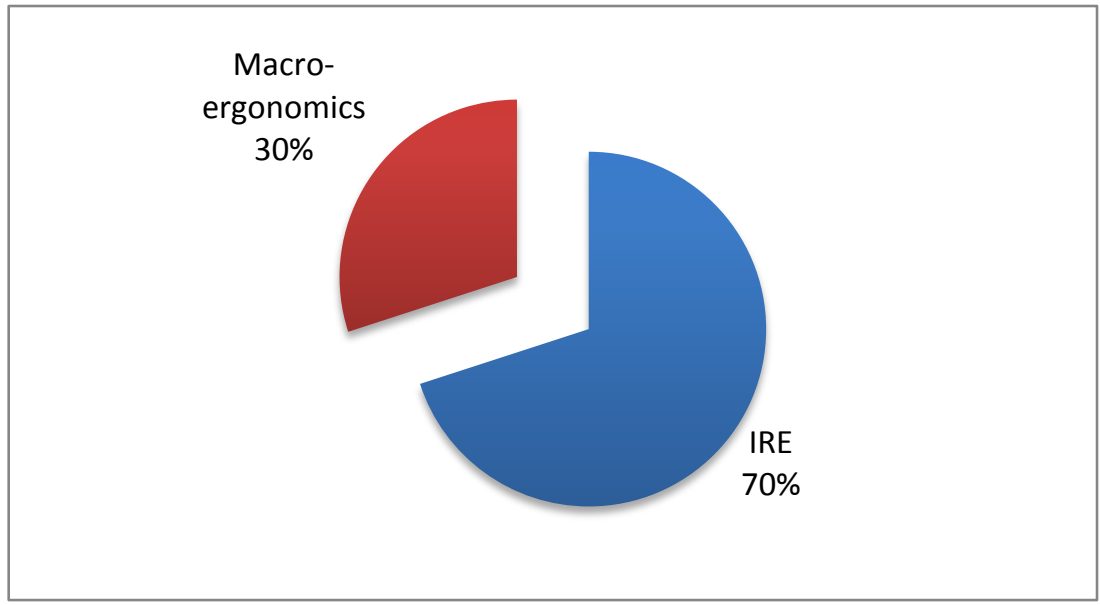

Figure 4: The importance of IRE and macro-ergonomics concepts

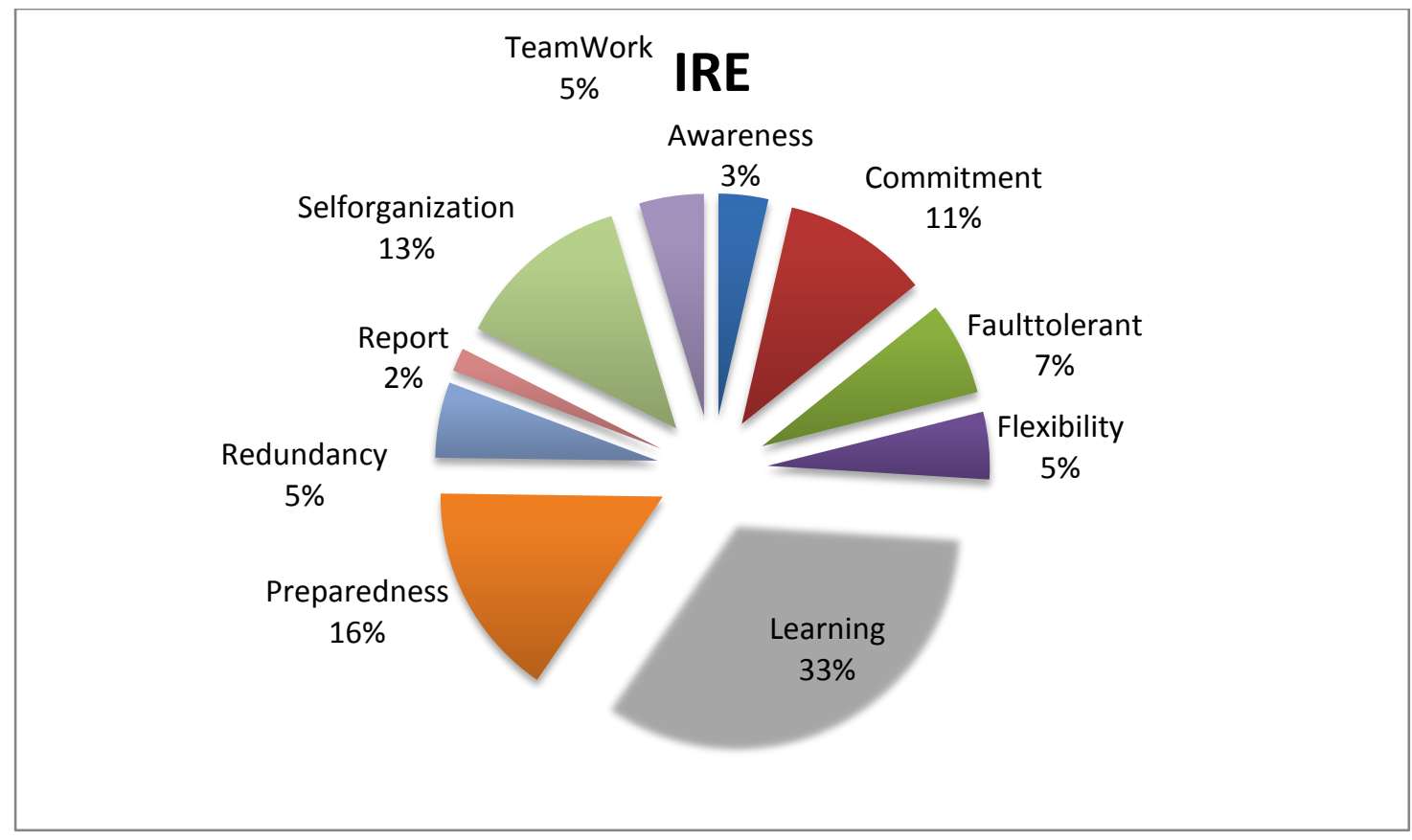

Figure 5: The importance of each RE indicator in this particular case study 


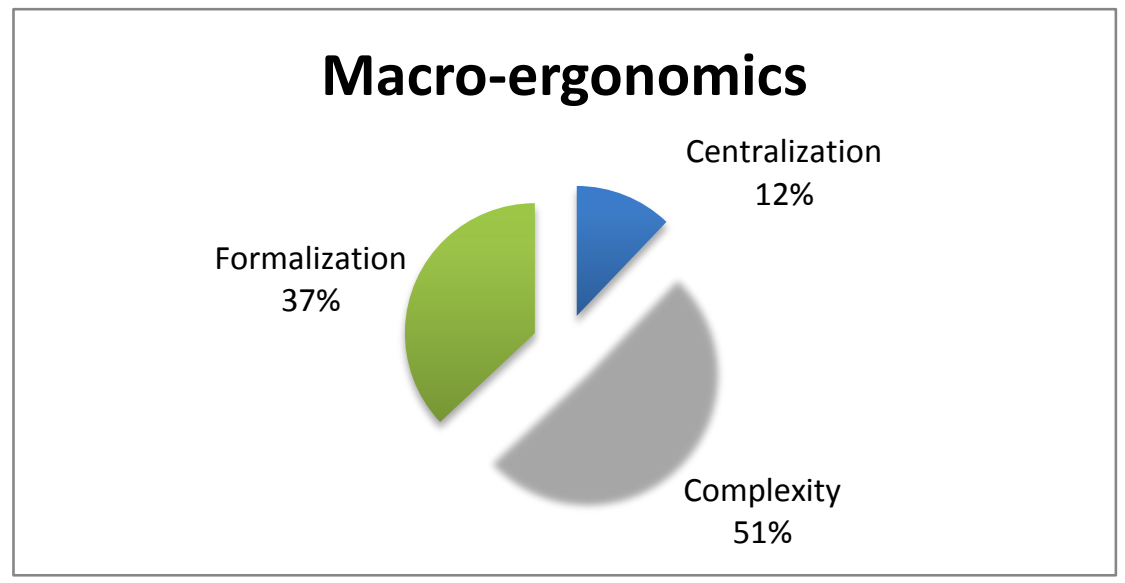

Figure 6: The importance of each macro-ergonomics indicator in this particular case study

In this section, ANOVA test is used to verify and validate the results of the previous step. The ANOVA results showed a p-value (significance $=0.001$ ) is less than the significance level $(\alpha=0.05)$; hence, the null hypothesis $(\mathrm{H} 0)$ is rejected. This indicates that there is a significant difference between the group means. Thus, it can be concluded that IRE factors are more effective than macro-ergonomic factors in this case study.

\subsection{The results of $P C A$}

In this section, each department of the proposed tile and ceramic factory is ranked by PCA method by considering IRE and macro-ergonomics factors in order to identify the performance of the departments. The DMUs which are used in this section have been shown in Table 2. The results of PCA technique including PCA scores and the rank of each DMU are indicated in Table 14. As it can be seen, DMU 10 (Printing department) has the highest score and its rank is the first. In addition, the results of NT approach and the rank of the DMUs are shown in Table 14. The results reveal that DMU 10 the best DMU based on the outcomes of NT method. In fact, the printing department has taken up the highest score by considering RE and macro-ergonomics factors in both approaches.

In final stage of this study, PCA and NT results are verified and validated by Spearman test. The Spearman correlation value is calculated by the following formula:

$r_{s}=1-\frac{6 \sum d_{i}^{2}}{N\left(N^{2}-1\right)}$ 
Where $\mathrm{N}=11$ and $\sum d_{i}^{2}$ is the summation of differences between the values of two approaches. The correlation between the results of PCA and NT is computed by means of Spearman test. The value of the test is equal to 0.864 and it means there is a strong relationship between PCA and NT in terms of the data set presented for these DMUs.

\begin{tabular}{|c|c|c|c|c|}
\hline \multicolumn{5}{|l|}{$\begin{array}{l}\text { Table } 14 \\
\text { PCA ranking }\end{array}$} \\
\hline DMU no. & PCA scores & PCA rank & NT scores & NT rank \\
\hline DMU 10 & 4.487 & 1 & 1.81 & 1 \\
\hline DMU 11 & 1.018 & 2 & 4.23 & 6 \\
\hline DMU 4 & 0.801 & 3 & 1.98 & 2 \\
\hline DMU 7 & 0.366 & 4 & 3.86 & 5 \\
\hline DMU 1 & 0.275 & 5 & 2.24 & 3 \\
\hline DMU 6 & -0.150 & 6 & 3.11 & 4 \\
\hline DMU 9 & -0.544 & 7 & 4.79 & 8 \\
\hline DMU 2 & -0.993 & 8 & 4.54 & 7 \\
\hline DMU 5 & -1.355 & 9 & 5.65 & 9 \\
\hline DMU 8 & -1.756 & 10 & 6.35 & 11 \\
\hline DMU 3 & -2.150 & 11 & 6.84 & 10 \\
\hline
\end{tabular}

\section{Conclusion}

Integrated Resilience engineering (IRE) is a novel concept for the safety improvement of complex systems, such as tile and ceramic factories. This study aimed to evaluate the impact of IRE and macro-ergonomics factors in a tile and ceramic factory. This is the first study that presents a comprehensive and robust design approach based on integrated macro-ergonomics and IRE in a tile and ceramic factory by means of DEA, identifies the impact of such integration on system performance by PCA, suggests a unique and integrated approach based on DEA, FDEA, PCA and ANOVA to meet the proposed objectives, identifies the weight of each factor through mathematical modeling method. Hence, this is a practical approach that may be used to identify weaknesses and strengths of such systems.

The FDEA model was used in this research to decrease the uncertainties existing in qualitative indicators. To this end, a standard questionnaire was first developed based on IRE and macro-ergonomics factors. Reliability and validity analyses approved the accuracy of the acquired data. The reliability coefficient was obtained equal to $70 \%$. Then, DEA and FDEA methods were applied to evaluate the performance of this particular case study. The best combination of macro-ergonomics factors for selecting the accurate output and input variables was determined through Friedman test. 
In this study, sensitivity analysis was performed to identify the impact of IRE and macroergonomics factors in a tile and ceramic factory. The results revealed that learning, complexity, formalization, and preparedness would respectively be the most important factors for this particular case study. Furthermore, ANOVA was employed for the verification and validation of the previous results (step 12th).

Weight of learning factor equaled 0.21 , which shows the importance of this factor in the improvement of performance efficiency. Planning for improvement learning, complexity, formalization, and preparedness can considerably improve the total performance of the proposed system. In addition, the effects of IRE and macro-ergonomics criteria were separately recognized through calculated values of efficiencies. These weights were calculated by percentage of change in efficiency score, which was produced by each factor. The results showed that the system efficiency would be improved by integrating IRE and macro-ergonomics factors. It was also shown that IRE factors were more effective than macro-ergonomics factors through ANOVA in this tile and ceramic factory. Hence, IRE plays a vital role in efficiency enhancement of this system. Afterwards, the departments of this tile and ceramic factory were ranked by means of PCA. Verification and validation of the results of PCA and NT approaches were done by Spearman test. The correlation between PCA and NT was computed equal to 0.864 that indicates a strong relationship among PCA and NT results. The results revealed that the printing department has the highest score in considering IRE and macro-ergonomic indices.

The proposed approach would help managers have a comprehensive understanding of the tile and ceramic factory with respect to the IRE and macro-ergonomics concepts. To show the advantages and superiorities of our study, features of this study were compared with those of previous models and studies as shown in Table 15. 


\begin{tabular}{|c|c|c|c|c|c|c|c|c|c|c|c|c|c|c|c|c|c|c|c|c|c|}
\hline \multicolumn{22}{|c|}{$\begin{array}{l}\text { Table } 13 \\
\text { The features of proposed methodology versus other studies }\end{array}$} \\
\hline & \multicolumn{13}{|c|}{ Elements } & \multicolumn{7}{|c|}{ Methodologies } & \multirow[b]{2}{*}{ 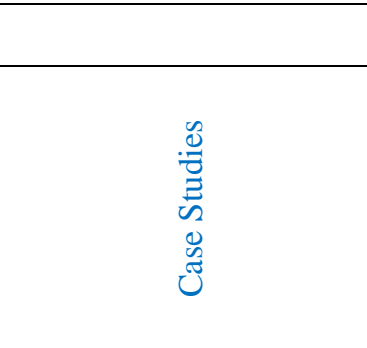 } \\
\hline 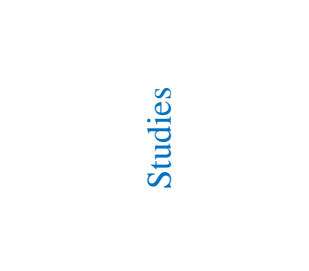 & 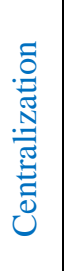 & 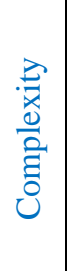 & 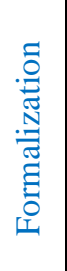 & 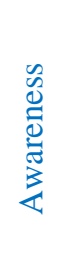 & 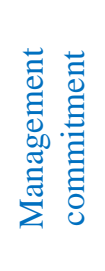 & 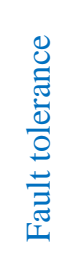 & 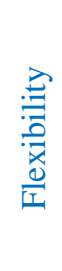 & & 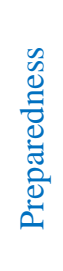 & 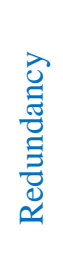 & & 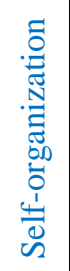 & 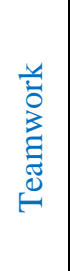 & 荇 & 空 & 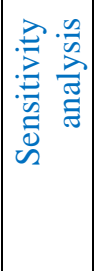 & 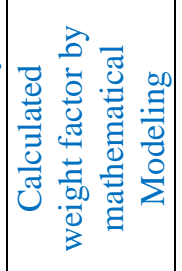 & 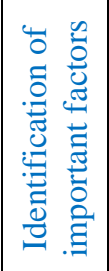 & 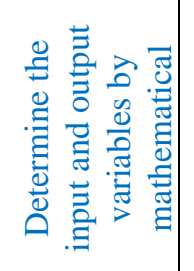 & 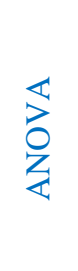 & \\
\hline This study & $\checkmark$ & $\checkmark$ & $\checkmark$ & $\checkmark$ & $\checkmark$ & $\checkmark$ & $\checkmark$ & $\checkmark$ & $\checkmark$ & $\checkmark$ & $\checkmark$ & $\checkmark$ & $\checkmark$ & $\checkmark$ & $\checkmark$ & $\checkmark$ & $\checkmark$ & $\checkmark$ & $\checkmark$ & $\checkmark$ & Tile and ceramic factory \\
\hline Kleiner (2008) & $\checkmark$ & $\checkmark$ & $\checkmark$ & & & & & & & & & & & & & & & & & & - \\
\hline Costella et al (2009) & & & & $\checkmark$ & $\checkmark$ & & $\checkmark$ & $\checkmark$ & & & & & & & & & & & & & $\begin{array}{l}\text { Automobile exhaust } \\
\text { factory }\end{array}$ \\
\hline Morel et al. (2009) & & & & $\checkmark$ & $\checkmark$ & & $\checkmark$ & $\checkmark$ & $\checkmark$ & & $\checkmark$ & & & & & & & & & & - \\
\hline Shirali et al. (2012) & & & & $\checkmark$ & $\checkmark$ & & & $\checkmark$ & $\checkmark$ & & $\checkmark$ & & & & & & & & & & Chemical factory \\
\hline Azadeh et al. (2013) & & & & $\checkmark$ & $\checkmark$ & $\checkmark$ & $\checkmark$ & $\checkmark$ & $\checkmark$ & $\checkmark$ & $\checkmark$ & $\checkmark$ & $\checkmark$ & $\checkmark$ & & $\checkmark$ & & & & & Petrochemical plant \\
\hline Saurin et al. (2014) & & & & $\checkmark$ & $\checkmark$ & & $\checkmark$ & $\checkmark$ & $\checkmark$ & & $\checkmark$ & & & & & & & & & & Electricity distributer \\
\hline Azadeh et al. (2015) & & & & $\checkmark$ & $\checkmark$ & & $\checkmark$ & $\checkmark$ & $\checkmark$ & & $\checkmark$ & & & $\checkmark$ & & $\checkmark$ & $\checkmark$ & $\checkmark$ & & & Petrochemical plant \\
\hline Azadeh et al. (2016) & & & & & & & & & & & & & $\checkmark$ & $\checkmark$ & & $\checkmark$ & $\checkmark$ & $\checkmark$ & & & An actual hospital \\
\hline
\end{tabular}




\section{References}

Andersen, P., Petersen, N.C., 1993. A procedure for ranking efficient units in data envelopment analysis. Management Science 39(10), 1261-1264.

Azadeh, A., 2007. Auto Assess Software and Manual. School of Industrial Engineering, University of Tehran, Iran.

Azadeh, A., Amalnick, M.,Ghaderi, S., Asadzadeh, S., 2007. An integrated DEA PCA numerical taxonomy approach for energy efficiency assessment and consumption optimization in energy intensive manufacturing sectors. Energy Policy 35, 3792-3806.

Azadeh, A., Bonab, N.A., Salehi, V., Zarrin, M., 2015. A unique algorithm for the assessment and improvement of job satisfaction by resilience engineering: Hazardous labs. International Journal of Industrial Ergonomics 49, 68-77.

Azadeh, A., Ghaderi, S.F., Nasrollahi, M.R., 2011. Location optimization of wind plants in Iran by an integrated hierarchical Data Envelopment Analysis. Renewable Energy 36(5), 1621-1631.

Azadeh, A., Ghaderi, S.F., Omrani, H., 2009. A deterministic approach for performance assessment and optimization of power distribution units in Iran. Energy Policy 37(1), 274-280.

Azadeh, A., Haghighi, S.M., Salehi, V., 2015. Identification of managerial shaping factors in a petrochemical plant by resilience engineering and data envelopment analysis. Journal of Loss Prevention in the Process Industries 36, 158-166.

Azadeh, A., Haghighi, S.M., Gaeini, Z., Shabanpour, N., 2016. Optimization of healthcare supply chain in context of macro-ergonomics factors by a unique mathematical programming approach. Applied Ergonomics 55, 46-55.

Azadeh, A., Salehi, V., 2014. Modeling and optimizing efficiency gap between managers and operators in integrated resilient systems: The case of a petrochemical plant. Process Safety and Environmental Protection 92(6), 766-778.

Azadeh, A., Salehi, V., Ashjari, B., Saberi, M., 2014. Performance evaluation of integrated resilience engineering factors by data envelopment analysis: the case of a petrochemical plant. Process Safety and Environmental Protection 92, 231-241.

Azadeh, A., Salehi, V., Kianpour, M., 2016. Performance evaluation of rail transportation systems by considering resilience engineering factors: Tehran railway electrification system, Transportation Letters, 1-14.

Azadeh, A., Salehi, V., Mirzayi, M., Roudi, E., 2017. Combinatorial optimization of resilience engineering and organizational factors in a gas refinery by a unique mathematical programming approach. Human Factors and Ergonomics in Manufacturing \& Service Industries 27 (1), 53-65.

Bedeian, A.G., Zammuto, R.F., 1991. Organizations: Theory and design. Chicago: Dryden.

Bertolini, M., 2007. Assessment of human reliability factors: a fuzzy cognitive maps approach. International Journal of Industrial Ergonomics 37, 405-413. 
Carayon, P., 2003. Macroergonomics in quality of care and patient safety. In: Luszac, H., Zink, K. (Eds.). Human Factors in Organizational Design and Management, 21-33.

Carayon, P., 2006. Human factors of complex sociotechnical systems. Applied Ergonomics $37(4), 525-535$.

Charnes, A., Cooper, W.W., Rhodes, E., 1978. Measuring the efficiency of decision making units. European Journal of Operational Research 2(6), 429-444.

Clarke, D.M., 2005. Human redundancy in complex, hazardous systems: a theoretical framework. Safety Science 43(9), 655-677.

Clegg, C.W., 2000. Sociotechnical principles for system design. Applied Ergonomics 31(5), 463-477.

Costella, M.F., Saurin, T.A., de Macedo Guimaraes, L.B., 2009. A method for assessing health and safety management systems from the resilience engineering perspective. Safety Science 47(8), 1056-1067.

Dinh, L.T., Pasman, H., Gao, X., Mannan, M.S., 2012. Resilience engineering of industrial processes: principles and contributing factors. Journal of Loss Prevention in the Process Industries 25(2), 233-241.

Frangopol, D.M., Curley, J.P., 1987. Effects of damage and redundancy on structural reliability. Journal of Structural Engineering 113(7), 1533-1549.

Fujita, Y., 2006. Resilient Systems. In: Hollnagel, E., Woods, D.D., Leveson, N. (Eds.), Resilience Engineering. Concepts and Precepts. Ashgate, Aldershot, UK.

Furniss, D., Back, J., Blandford, A., Hildebrandt, M., Broberg, H., 2011. A resilience markers framework for small teams. Reliability Engineering and System Safety 96(1), 2-10.

Hair, J.R., Anderson, R.E., Tatham, R.L., Black, W.C., 1998. Multivariate Data Analysis. NJ: Prentice Hall International Inc, pp. 326-338.

Haydee, S., Herrera, M., Huatuco, L.H., 2011. Macro-ergonomics Intervention Programs: Recommendations for Their Design and Implementation. Human Factors and Ergonomics in Manufacturing \& Service Industries, 21 (3), 227-243.

Hendrick, H.W., 1986a. Macroergonomics: A conceptual model for integrating human factors with organizational design. In: O. Brown, Jr. \& H. W. Hendrick (Eds.). Human factors in organizational design and management, Amsterdam: North-Holland, pp. 467478.

Hendrick, H.W., 1986b. Macro-ergonomics: A concept whose time has come. Human Factors Society Bulletin 30(2), 1-3.

Hendrick, H.W., 1997. Organizational design and macro-ergonomics. In: G. Salvendy (Eds.), Handbook of human factors and ergonomics (2nd ed.), New York: Wiley, pp. 594-636.

Hendrick, H.W., Kleiner, B.M., 2001. Macro-ergonomics: An Introduction to Work System Design. Santa Monica, CA: Human Factors and Ergonomics Society. 
Hendrick, H.W., Kleiner, B.M., 2002. Macro-ergonomics: Theory, Methods, and Applications. Mahwah, NJ: Lawrence Erlbaum Associates, Publishers.

Hendrick, H.W., 1995. Future directions in macro-ergonomics. Ergonomics 38(8), 1617 1624.

Hendrick, H.W., 2002. An overview of macro-ergonomics. In: Hendrick, H.W., Kleiner, B.M. (Eds.), Macro-ergonomics: Theory, Methods, and Applications. Lawrence Erlbaum Associates, Mahwah, NJ, pp. 1-23.

Hollnagel, E., Woods, D., Leveson, N., 2006. Resilience Engineering: Concepts and Precepts. Ashgate, Aldershot, UK, pp. 275-286.

Huber, S., Wijgerden, I.V., Witt, A.D., Dekker, S.W., 2009. Learning from organizational incidents: Resilience engineering for high-risk process environments. Process Safety Progress 28(1), 90-95.

Ingelgard, A., Norrgren, F., 2001. Effects of change strategy and top-management involvement on quality of working life and economic results. International Journal of Industrial Ergonomics 27(2), 93-105.

Katz, D., Kahn, R., 1966. The Social Psychology of Organizations. New York: Wiley.

Kleiner, B.M., 2008. Macroergonomics: work system analysis and design. Human Factors: The Journal of the Human Factors and Ergonomics Society 50(3), 461-467.

Kosko, B., 1986. Fuzzy cognitive maps. International Journal of Man-Machine Studies 24(1), 65-75.

Kusiak, A., Tseng, B.T.L., 2000. Data mining in engineering design: a case study. In: Proceedings of the IEEE International Conference on Robotics and Automation 1, pp. 206-211.

Ling, F.L., Duan, S.Y., 2010. On fault-tolerant control of dynamic systems with actuator failures and external disturbances. Acta Automatica Sinca 36(11), 1620-1625.

Madni, A.M., Jackson, S., 2009. Towards a conceptual framework for resilience engineering. Systems Journal 3(2), IEEE, 181-191.

Meshkati, N., 1991. Critical Human and Organizational Factors: Considerations for Design and Operation of Petrochemical Plants. In: SPE Health, Safety and Environment in Oil and Gas Exploration and Production Conference. Society of Petroleum Engineers.

Morel, G., Amalberti, R., Chauvin, C., 2009. How good micro/macro ergonomics may improve resilience, but not necessarily safety. Safety Science 47(2), 285-294.

Murphy, L.A., Robertson, M.M., Carayon, P., 2014. The next generation of macroergonomics: Integrating safety climate. Accident Analysis and Prevention 68, 16-24.

Nagamachi, M., 1995. Requisites and practices of participatory ergonomics. International Journal of Industrial Ergonomics, 15(5), 371-377. 
Olson, E.M., Slater, S.F., Hult, G.T.M., 2005. The performance implications of fit among business strategy, marketing organization structure, and strategic behavior. Journal of Marketing 69(3), 49-65.

Plowman, D.A., Solansky, S., Beck, T.E., Baker, L., Kulkarni, M., Travis, D.V., 2007.The role of leadership in emergent, self-organization. The Leadership Quarterly 18(4), 341356.

Qureshi, Z.A, 2007. Review of accident modeling approaches for complex socio-technical systems. Australian Computer Society, Inc. 47-59.

Reason, J., 1997. Managing the risks of organizational accidents. Hants, England: Ashgate Publishing Ltd.

Robbins, S.R., 1983. Organization theory: The structure and design of organizations. Englewood Cliffs, NJ: Prentice Hall.

Saati, S.M., Memariani, A., Jahanshahloo, G.R., 2002. Efficiency analysis and ranking of DMUs with fuzzy data. Fuzzy Optimization and Decision Making 1(3), 255-267.

Saurin, T.A., Wachs, P., Righi, A.W., Henriqson, E., 2014. The design of scenario-based training from the resilience engineering perspective: A study with grid electricians. Accident Analysis and Prevention 68, 30-41.

Serugendo, G., 2009. Robustness and dependability of self-organizing systems-a safety engineering perspective. In: Proceedings of the 11th International Symposium on Stabilization, Safety, and Security of Distributed Systems, Lyon, France.

Shirali, G.A., Mohammadfam, I., Ebrahimipour, V., 2013. A new method for quantitative assessment of resilience engineering by PCA and NT approach: A case study in a process industry. Reliability Engineering and System Safety 119, 88-94.

Shirali, G.H.A., Motamedzade, M., Mohammadfam, I., Ebrahimipour, V., Moghimbeigi, A., 2012. Challenges in building resilience engineering (RE) and adaptive capacity: A field study in a chemical plant. Process Safety and Environmental Protection 90(2), 83-90.

Steen, R., Aven, T., 2011. A risk perspective suitable for resilience engineering. Safety Science 49(2), 292-297.

Stevenson, W.B., 1993. Organizational design. In: R.T. Golembiewski (Eds.), Handbook of organizational behavior. New York: Marcel Dekker, pp. 141-168.

Woods, D.D., Hollnagel, E., 2006. In: Hollnagel, E., Woods, D.D., Leveson, N. (Eds.), Prologue: Resilience Engineering Concepts, Resilience Engineering: Concepts and Precepts. Ashgate Publishing Co., Aldershot, pp. 3-6.

Wreathall, J., 2006. Properties of resilient organizations: an initial view. In: Hollnagel, E., Woods, D., Leveson, N. (Eds.), Resilience Engineering: Concepts and Precepts. Ashgate, Aldershot, UK, pp. 275-286.

Xyrichis, A., Ream, E., 2008. Teamwork: a concept analysis. Journal of Advanced Nursing 61(2), pp. 232-241. 